\title{
Epidemiological aspects of colorectal cancer in East Azerbaijan, Northwest Iran: five year survival analysis
}

\author{
Ramin Barnous ${ }^{1}$, Mohammad Hossein Somi ${ }^{1}$, Zohreh Sanaat ${ }^{2}$, Pooneh Jabbaripoor ${ }^{1}$, \\ Neda Dolatkhah ${ }^{3}$, and Roya Dolatkhah ${ }^{2 *}$
}

\begin{abstract}
\section{BACKGROUND}

Colorectal cancer (CRC) is the third most common cancer and the second leading cause of death from cancer in the world. Currently, CRC is the fourth most common cancer in men and the second common cancer in women of all ages in Iran. The aim of this study was to determine the epidemiologic profile of CRC along with $\mathrm{CRC}$ specific survival analysis.
\end{abstract}

\section{METHODS}

This was an analytical cross-sectional study using the East Azerbaijan Population Based Cancer Registry database (EA-PBCR) as a source for data related to patients with a diagnosis of CRC. Colorectal cancer specific 1- to 5-year survival analysis and mortality rates were calculated. Log-rank test and Cox regression analysis was performed to test the equality of survival function and mortality hazard.

\section{RESULTS}

A total of 2,366 newly diagnosed CRCs were registered during 3 years, with a male: female ratio of 1.31 . Overall survival rate was $49.8 \%$. One- to 5-year survival rates were $96.21 \%, 56.94 \%, 48.62 \%, 47.88 \%$ and $46.76 \%$ respectively. At multivariate level, after adjusting for all variables, regression analysis showed that the hazard of mortality in stage IV cancers was 46.44 times higher than that in stage I cancers $(\mathrm{HR}=46.44,95 \% \mathrm{CI}$ : $14.86-145.14, \mathrm{p}=0.000)$. However, differences in patients' age group and sex and the subsite of cancer did not create any statistically significant variation between groups in regards to mortality hazards $(\mathrm{p}>0.05)$.

\section{CONCLUSION}

This study demonstrated that the stage and grade of CRC were important prognostic factors and that early screening and diagnosis of CRC were essential.

Keywords: Colorectal cancer, epidemiology, survival, prognosis, East Azerbaijan
${ }^{1}$ Liver and Gastrointestinal Diseases Research Center, Tabriz University of Medical Sciences, Tabriz, Iran

${ }^{2}$ Hematology and Oncology Research Center, Tabriz University of Medical Sciences, Tabriz, Iran

${ }^{3}$ Physical Medicine and Rehabilitation Research Center, Aging Research Institute, Tabriz University of Medical Sciences, Tabriz, Iran

*Correspondence :

Roya Dolatkhah, MD PhD

Postal address: Hematology and Oncology Research Center, Tabriz University of Medical Sciences, Tabriz, Iran

Postal code/ P.O. Box: 5166614731 Telephone number: +984133361358 Email: royadolatkhah@yahoo.com ORCID ID: 0000-0002-6897-7120

Date of first submission, April 7, 2021 Date of final revised submission, August 25, 2021

Date of acceptance, August 30, 2021

This open access article is distributed under a Creative Commons AttributionNon Commercial-Share Alike 4.0 International License

Cite this article as: Barnous $\mathrm{R}$, Somi MH, Sanaat Z, Jabbaripoor P, Dolatkhah N, Dolatkhah R. Epidemiological aspects of colorectal cancer in East Azerbaijan, Northwest Iran: five year survival analysis. Univ Med 2021;40:190-9. doi: 10.18051/ UnivMed.2021.v40.190-199 


\section{INTRODUCTION}

According to the latest report of the International Agency for Research on Cancer in 2020, colorectal cancer (CRC) is the third most common cancer and the second leading cause of death from cancer in the world. ${ }^{(1)}$ The incidence rate is three times higher in developed countries, but due to higher mortality in developing countries, there is a smaller gap in mortality rates. ${ }^{(2)}$ Currently, colorectal cancer is the fourth most common cancer in men and the second common cancer in women of all ages in Iran. ${ }^{(3)}$ Globally three patterns are identifiable in relation to development when it comes to CRC mortality and incidence trends: 1) an increase in incidence and mortality trends; 2) increasing incidence but decreasing mortality trends; 3 ) a decrease in mortality and incidence trends. ${ }^{(2,4)}$ In Iran there was an increase in the agestandardized incidence rates (ASRs) for CRC in 2012-2015, and their incidence is moving in an upward manner. ${ }^{(5-7)}$ In East Azerbaijan province CRC is the second most common cancer in both sexes, with an overall incidence rate of 20.2 and 16.2 per 100000 respectively in men and women. ${ }^{(8)}$ East Azerbaijan province has the $4^{\text {th }}$ place among Iran's provinces when it comes to CRC ASRs, and is the only province in North/Northwest Iran with an ASR higher than $20(\mathrm{ASR}=20.77)$. However, the highest ASR was reported from Semnan $(\mathrm{ASR}=24.29)$, a province located in Central Iran, and the lowest is for Kohkiloye-boyerahmad ( $\mathrm{ASR}=6.39)$, in Central Iran. ${ }^{(6)}$

Comprehensive overviews revealed a significant increasing trend in CRC incidence in Iran, ${ }^{(5)}$ but systematic analysis of survival rates in different regions of the country revealed that the prognosis of CRC patients in Iran was better than that in similar Asian countries. The pooled 5 -year survival rates were reported to be $33.6 \%$ in India and 34.3\% in Malaysia, which 5-year survival rate was estimated at 0.54 (95\% CI: 0.49 0.58 ) in Iran. ${ }^{(9)}$ The highest 5-year survival rate was reported to be $84.6 \%$ from Kermanshah
(West Iran), and the lowest was 27.02 from Shiraz (South Iran). On the other hand, multivariate model analysis revealed a significant improvement in the prognosis of CRC patients during the study period. ${ }^{(9-11)}$ Since CRC has a high incidence and cancer-related mortality in Iran and East Azerbaijan province, it is necessary to have an epidemiological study of the incidence, sex, age distribution and morphological types of colorectal cancer. The aim of the present study was to determine the most recent epidemiological profile of colorectal cancer along with 1- to 5year colorectal cancer specific survival in East Azerbaijan, Northwest Iran.

\section{METHODS}

\section{Research design}

This was an analytical cross-sectional study using the East Azerbaijan Population Based Cancer Registry database (EA-PBCR) as a source for data related to patients with a diagnosis of colorectal cancer in East Azerbaijan province. The EA-PBCR database includes the data from all newly- diagnosed cancer patients, from March $20^{\text {th }} 2015$ to March $19^{\text {th }} 2017$ (3 Iranian solar years); encompassing the data collected from cancer related databases, including reports from pathology laboratories, hospital records, radiotherapy centers, and the death registry database.

\section{Study subjects}

East Azerbaijan is a province in Northwest Iran and is one of the most populated provinces in Iran with a population of around 4 million people -at the time of performing this study- most of whom are of Azeri ethnicity. As we used the EAPBCR database, all newly diagnosed colorectal cancer patients during three years of study were included in the study, so we did not have any sample size determination. We included all cases with confirmed primary and newly diagnosed colorectal cancer for each year of the study from different data sources. We excluded any duplicated cases by checking the patients' national 
identification number (NID), first name, family name and fathers' name. Also we evaluated any cancer cases with invasion, metastasis, or recurrence according to the morphology and behavior of the cancers, to avoid any missed and/ or duplicated cancer data.

\section{Data collection}

This database includes patients' data from three main aspects namely patient, tumor and data source. Patient demographic information included name, NID, birth date, sex, place of residence, date of first diagnosis and fathers' name. Tumor information included the morphology (histology, behavior, stage and grade) and topography (primary site of tumor), the latter being coded and collected in accordance with the International Classification of Disease for Oncology (ICD-O$3)$. Also contact information and data sources were recorded.

We performed statistical analysis and consistency check to ensure that the data were non-duplicated. Follow-up data and the data related to patient outcomes were obtained through contacting patients/relatives, and from Hospital Information System (HIS), although these data were not available for all patients.

\section{Outcome of the study}

The primary outcome of interest was colorectal cancer specific overall survival (OS), defined as the time from CRC diagnosis to date of death or date of last follow-up. Also overall mortality rate and one- to 5-year survival rates were obtained.

\section{Statistical analysis}

Colorectal cancer specific 1- to 5-year survival and mortality rates were calculated using STATA MP 14.2 (Stata Corp LP, College Station, Texas 77845 USA). Survival was calculated from the date of diagnosis to the date of cancer-related death, and/or the last follow-up time.

The final follow-up date of the patients was September $30^{\text {th }}, 2020$. Survival analysis was performed using the Kaplan-Meier method and life tables for 1- to 5-year survival data. Logrank test and Cox regression were used to test the equality of survival function and mortality hazard (HR, with $95 \%$ C.I.) by age, sex, morphology, subsite, stage and grade. Statistical significance was set at a value of $\mathrm{p}<0.05$.

\section{Ethical clearance}

The Ethics Committee of Tabriz University of Medical Sciences approved this study as a confirmed research project (Code: IR.TBZMED.REC.1398.1002). In line with the ethics rules of EA-PBCR, all patient information and records were kept confidential.

\section{RESULTS}

\section{Characteristics of the studied population}

The total number of CRC patients diagnosed in this 3-year period was 2,366; of these, 701 (29.63\%), $870(36.77 \%)$ and $795(33.60 \%)$ were diagnosed during 2015, 2016 and 2017 respectively. The male: female ratio was 1.31 and 1344 patients $(56.80 \%)$ were male and 1022 $(43.20 \%)$ female. The mean age of the patients was $63.37 \pm 14.26$ years, with the youngest and oldest patients being 14 and 96 years old respectively, while 601 patients $(25.40 \%)$ were in the $7^{\text {th }}$ decade of their lives.

Data about the stage and the grade of the cancers were available in 1722 and 1832 cases, respectively; $0.41 \%$ ( 7 patients) were in stage 0 , $7.90 \%$ (136 patients) in stage I, $23.98 \%$ (413 patients) in stage II, $35.71 \%$ (615 patients) in stage III and 32\% (551 patients) were in stage IV. As for grading, 1023 cases $(55.84 \%)$ were in grade I, 671 cases $(36.63 \%)$ in grade II and 138 cases $(7.53 \%)$ were in grade III of colorectal cancer. The most common morphological type was adenocarcinoma (AC) $(\mathrm{n}=1681,71.05 \%)$. As for topography, the majority of cases (1018$43.03 \%$ ) were not otherwise specified (NOS), followed by cancers of the anus and rectum (726$30.68 \%$ ) (Table 1). 
Table1. Distribution of characteristics and pathologic parameters of total cohort and cohort with follow-up of studied population

\begin{tabular}{lcc}
\hline Characteristic & $\begin{array}{c}\text { Total Cohort } \\
(\mathbf{n}=\mathbf{2 3 6 6})\end{array}$ & $\begin{array}{c}\text { Cohort with Follow-up } \\
(\mathbf{n}=\mathbf{1 4 2 5})\end{array}$ \\
\hline Age (years) & $63.37 \pm 14.26$ & $62.48 \pm 13.959$ \\
$\quad$ mean $( \pm$ SD) & $14-96$ & $14-96$ \\
range & $318(13.44 \%)$ & $179(12.56 \%)$ \\
$\leq 50$ & $2048(86.56 \%)$ & $1246(87.44 \%)$ \\
$>50$ & & \\
Sex & $1344(56.80 \%)$ & $821(57.61 \%)$ \\
Male & $1022(43.20 \%)$ & $604(42.39 \%)$ \\
Female & & \\
Subsite & $239(10.10 \%)$ & $161(11.30 \%)$ \\
Proximal colon & $383(16.19 \%)$ & $257(18.04 \%)$ \\
Distal colon & $726(30.68 \%)$ & $462(32.42 \%)$ \\
Rectum, anal canal & $1018(43.03 \%)$ & $545(38.25 \%)$ \\
NOS & & \\
Morphology & $1681(71.05 \%)$ & $996(69.89 \%)$ \\
AC & $68(2.87 \%)$ & $59(4.14 \%)$ \\
Mucinous AC & $530(22.40 \%)$ & $311(21.82 \%)$ \\
NOS & $87(3.68)$ & $59(4.14 \%)$ \\
Others & & \\
Grade & $1023(55.84 \%)$ & $739(54.10 \%)$ \\
I & $671(36.63 \%)$ & $512(37.48 \%)$ \\
II & $138(7.53 \%)$ & $115(8.42 \%)$ \\
III & Total (n=1832) & Total $(\mathrm{n}=1366)$ \\
Stage & & $70(5.22 \%)$ \\
I & $143(8.30 \%)$ & $286(21.34 \%)$ \\
II & $413(23.98 \%)$ & $495(36.94 \%)$ \\
III & $615(35.71 \%)$ & $489(36.49 \%)$ \\
IV & $551(32.00 \%)$ & Total $(\mathrm{n}=1340)$ \\
\hline
\end{tabular}

AC: adenocarcinoma; NOS: not otherwise specified

\section{Survival analysis}

Due to lack of contact information for 941 patients, we were able to perform survival analysis for 1,425 cases only. Of these, in the 5year follow-up period, $715(50.2 \%)$ patients died, giving an overall survival rate of $49.8 \%$. One- to 5-year survival rates were $96.21 \%, 56.94 \%$, $48.62 \%, 47.88 \%$ and $46.76 \%$ respectively. The overall mortality rate was 19.99 per 100,000 people, and mean follow-up time was 35.29 months (95\% CI: 34.21-36.38) (Table 2).

Table 2. Summary of statistics of 1425 cases included in survival analysis during three years of study

\begin{tabular}{lccccc}
\hline $\begin{array}{c}\text { Years of } \\
\text { study }\end{array}$ & Case (\%) & No. of events* (\%) & $\begin{array}{c}\text { Mortality } \\
\text { rate/100,000 }\end{array}$ & $\begin{array}{c}\text { Overall } \\
\text { survival (\%) }\end{array}$ & $\begin{array}{c}\text { Mean } \\
\text { follow up } \\
\text { time }\end{array}$ \\
\hline 2015 & $190(13.33)$ & $108(15.10)$ & 19.84 & 43.2 & 28.64 \\
2016 & $566(39.71)$ & $254(35.52)$ & 16.96 & 55.1 & 34.55 \\
2017 & $669(46.94)$ & $353(49.37)$ & 22.99 & 47.2 & 25.94 \\
Total & 1425 & 715 & 19.99 & 49.8 & 35.29 \\
\hline
\end{tabular}

* Event $=$ death 
As for survival functions, there was a significant difference in regard to the grade and stage of the cancers ( $p$ log-rank $=0.000$ - for both the grade and the stage of the cancer). Also, the effects of morphological type ( $\mathrm{p}$ logrank $=0.000)$ and the subsite of tumor ( $p \log$ rank $=0.012$ ) on survival functions, showed a

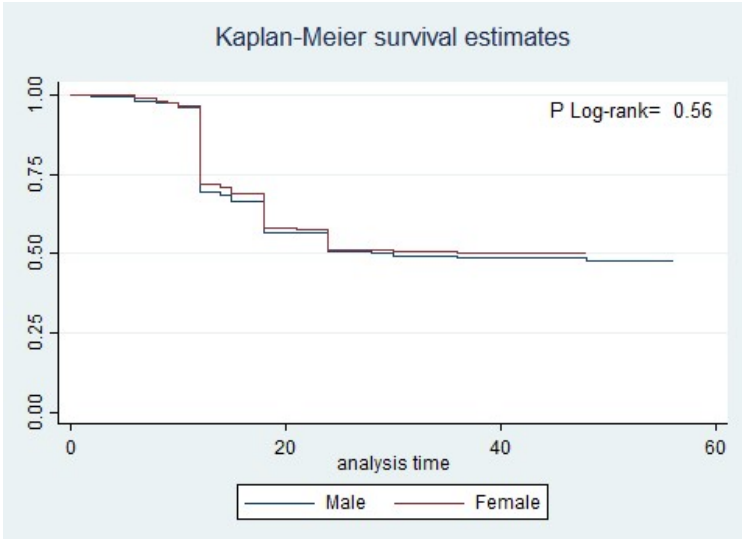

(a)

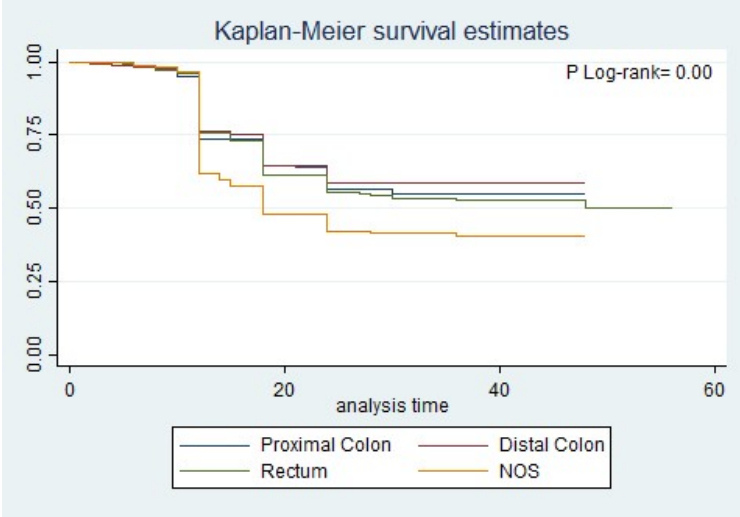

(c)

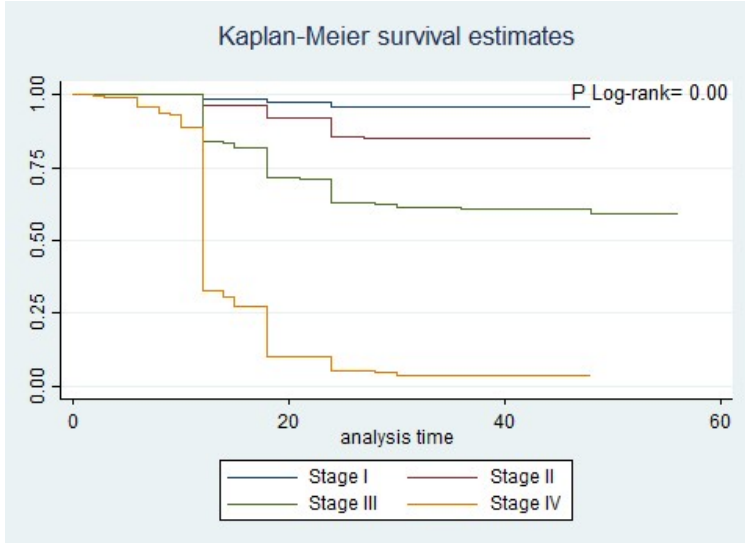

(e) statistical significance. However, the effects of age group ( $\leq 50$ years and $>50$ years) and sex on survival functions was not statistically significant. ( $\mathrm{p} \log$-rank $=0.538$ and 0.562 respectively) (Figure-1) Detailed results of univariate and multivariate Cox regression analysis are presented in Table 3.

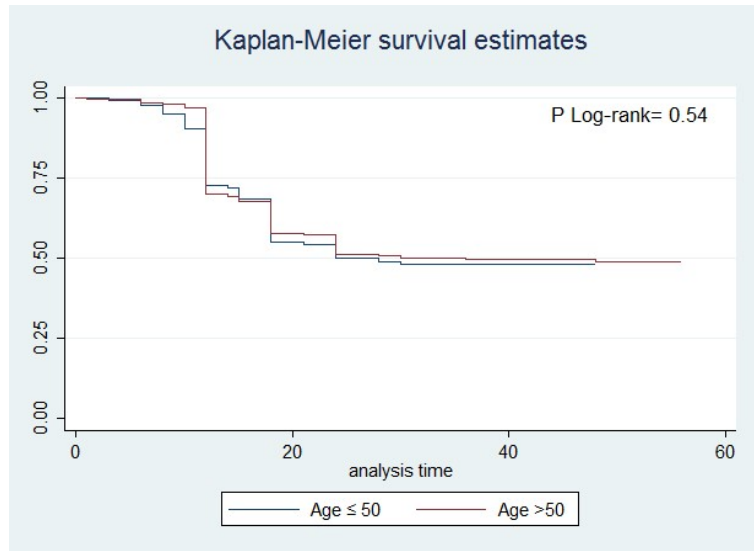

(b)

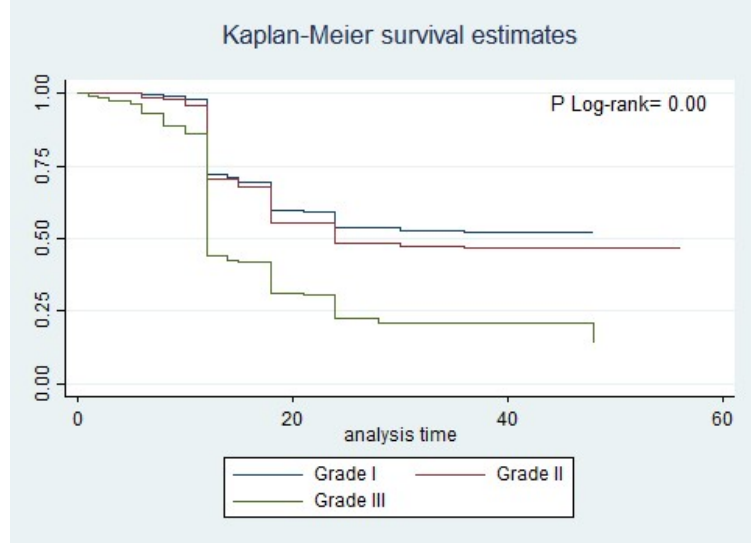

(d)

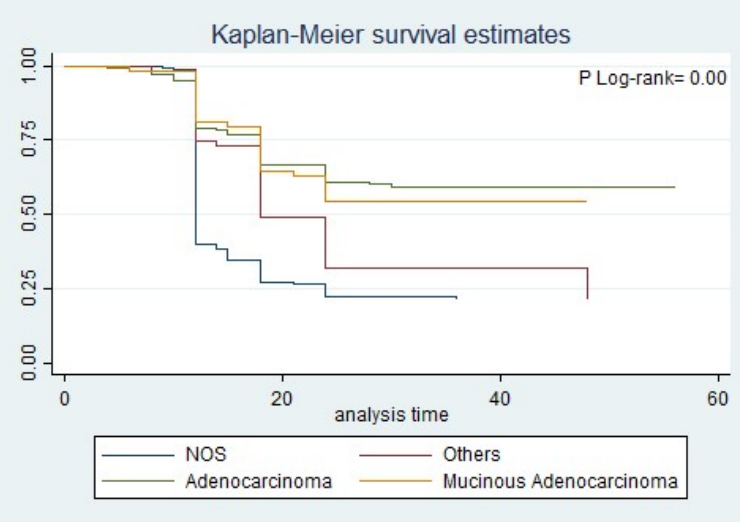

(f)

Figure 1: Kaplan-Meier survival curve, results for the test of equality of colorectal cancer-speciûc survival functions for the diûerent variables in Northwest Iran in (a) sex (b) age groups, (c) subsite groups, (d) grades, (e) stages and (f) morphologic types 
Table 3. Univariate and multivariate analysis with significant baseline characteristics (Cox proportional hazards regression, Breslow method for ties)

\begin{tabular}{|c|c|c|c|c|c|c|c|c|c|}
\hline \multirow[b]{2}{*}{ Variable } & \multicolumn{5}{|c|}{ Univariate Cox Regression } & \multicolumn{4}{|c|}{ Multivariate Cox Regression* } \\
\hline & n $(\%)$ & $\mathbf{H R}^{\dagger}$ & $\begin{array}{r} \\
\text { Con } \\
\text { In }\end{array}$ & $\begin{array}{l}\% \\
\text { dence } \\
\text { rval }\end{array}$ & p value & $\mathbf{H R}^{*}$ & $\begin{array}{r}9 \\
\text { Conf } \\
\text { Int }\end{array}$ & $\begin{array}{l}\text { o } \\
\text { lence } \\
\text { val }\end{array}$ & p value \\
\hline \multicolumn{2}{|l|}{ Age (years) } & & & & & & & & \\
\hline$\leq 50$ & $179(12.56)$ & Ref. & - & - & - & Ref. & - & - & - \\
\hline$>50$ & $1246(87.44)$ & 0.93 & 0.75 & 1.16 & 0.578 & 1.01 & 0.80 & 1.26 & 0.908 \\
\hline \multicolumn{10}{|l|}{ Sex } \\
\hline Male & $821(57.61)$ & Ref. & - & - & - & Ref. & - & - & - \\
\hline Female & $604(42.39)$ & 0.96 & 0.82 & 1.11 & 0.601 & 0.86 & 0.74 & 1.00 & 0.058 \\
\hline \multicolumn{10}{|l|}{ Subsite } \\
\hline Proximal Colon & $161(11.30)$ & Ref. & - & - & - & Ref. & - & - & - \\
\hline Distal Colon & $257(18.04)$ & 0.90 & 0.67 & 1.22 & 0.526 & 0.92 & 0.68 & 1.25 & 0.626 \\
\hline Rectum, Anal canal & $462(32.42)$ & 1.05 & 0.80 & 1.37 & 0.693 & 0.92 & 0.68 & 1.17 & 0.443 \\
\hline NOS & $545(38.25)$ & 1.45 & 1.12 & 1.87 & 0.004 & 0.99 & 0.76 & 1.30 & 0.993 \\
\hline \multicolumn{10}{|l|}{ Stage } \\
\hline I & $70(5.22)$ & Ref. & - & - & - & Ref. & - & - & - \\
\hline II & $286(21.34)$ & 3.54 & 1.09 & 11.44 & 0.034 & 3.35 & 1.04 & 10.83 & 0.043 \\
\hline III & 495 (36.94) & 10.77 & 17.01 & 33.71 & 0.000 & 10.09 & 3.22 & 31.60 & 0.000 \\
\hline IV & 489 (36.94) & 53.05 & 17.01 & 165.42 & 0.000 & 46.44 & 14.86 & 3.33 & 0.000 \\
\hline \multicolumn{10}{|l|}{ Grade } \\
\hline I & $739(54.10)$ & Ref. & - & - & - & Ref. & - & - & - \\
\hline II & $512(37.48)$ & 1.14 & 0.97 & 1.34 & 0.089 & 1.07 & 0.91 & 1.25 & 0.394 \\
\hline III & $115(8.42)$ & 2.25 & 1.78 & 2.83 & 0.000 & 1.24 & 0.98 & 1.57 & 0.069 \\
\hline \multicolumn{10}{|l|}{ Morphology } \\
\hline NOS & $311(21.82)$ & Ref. & - & - & - & Ref. & - & - & - \\
\hline Others & $59(4.14)$ & 0.69 & 0.49 & 0.97 & 0.033 & 0.75 & 0.53 & 1.06 & 0.111 \\
\hline $\mathrm{AC}$ & 996 (69.89) & 0.38 & 0.32 & 0.45 & 0.000 & 0.54 & 0.49 & 0.71 & 0.000 \\
\hline Mucinous AC & $59(4.14)$ & 0.42 & 0.28 & 0.63 & 0.000 & 0.59 & 0.39 & 0.90 & 0.014 \\
\hline
\end{tabular}

Notes: "unadjusted hazard ratio; *adjusted hazard ratio; **total p-value; Abbreviations: HR: hazard ratio; CI: confidence interval; Cox regression - Breslow method for ties, $\mathrm{p}$ value $\leq 0.05$; AC: adenocarcinoma; NOS: not otherwise specified

Cox regression analysis at univariate level showed that as expected, in comparison with lower cancer stages, higher stages had a significantly higher mortality hazard $(\mathrm{HR}=53.05$; 95\% CI:17.01-165.342; $\mathrm{p}=0.000$ ) for stage IV vs. stage I. These effects are the same for cancer grading, as the mortality hazard for grade III was 2.25 times higher than for grade I. $(\mathrm{HR}=2.25$; 95\% CI: $1.78-2.83 ; \mathrm{p}=0.000)$

At multivariate level, after adjusting for all variables, regression analysis showed that the hazard of mortality in stage IV cancers were 46.44 times higher $(\mathrm{HR}=46.44$; 95\% CI:14.86145.14; $\mathrm{p}=0.000)$, in stage III cancers 10.06 time higher $(\mathrm{HR}=10.09 ; 95 \% \mathrm{CI}: 3.22-3160, \mathrm{p}=0.000)$, and in stage II cancers 3.35 times higher $(\mathrm{HR}=3.35 ; 95 \% \mathrm{CI}: 1.04-10.83, \mathrm{p}=0.043)$ than in stage I cancers. However, differences in age group, sex and subsite of cancer among patients did not create any statistically significant variation between groups in regards to mortality hazards.

\section{DISCUSSION}

The number of newly diagnosed colorectal cancers in East Azerbaijan province during the 3 -year period of study was 2,366 cases. Adenocarcinoma had the highest proportion (1681, 71.05\%); cancers of the rectum and anal canal $(726,30.68 \%)$ were the most frequent. In East Azerbaijan colorectal cancer ranked second among most common cancers both in men and women with an ASR of 18.2 and 13.7 respectively. ${ }^{(8)}$ This, alongside the increasing trend of the incidence of colorectal cancer in Iran shows the importance of an extended epidemiologic analysis on colorectal cancer. ${ }^{(12)}$ Recently colorectal cancer was the third highest 
incidence cancer in Iran in terms of incidence, crude rate and age-standardized incidence rate (ASIR), which had a $41 \%$ increase since 2000 , with a sex transition in the incidence pattern which was higher in women than men. ${ }^{(13)}$ We aimed to determine the epidemiologic profile of colorectal cancer along with 1 - to 5-year colorectal cancer specific survival analysis in East Azerbaijan, Iran.

Colorectal cancer is the second among cancer-related deaths and occupies the third place in terms of worldwide incidence. As reported in GLOBOCAN 2020, colorectal cancer deaths account for $9.4 \%$ of all cancer deaths in the world (935,000 deaths). ${ }^{(1)}$ Colorectal cancer has a higher incidence in developed countries ${ }^{(2)}$ and there is also an increase in the incidence rate of several types of cancer, including colorectal, prostate and breast cancer in low and middle-income countries..$^{(1,14)}$ In Iran, as a developing country, cancers are the third leading cause of death; there has been an increase in the incidence of colorectal cancers in Iran over the past decade. ${ }^{(13)}$ Colorectal cancers have a higher incidence in Central Iran and the highest ASR in both men and women has been reported from Semnan, a province in Central Iran (24.29 and 16.64 per 100000 respectively), closely followed by East Azerbaijan province which also has a high ASR for colorectal cancer (20.77 and 15.69 for men and women respectively), ${ }^{(15)}$ being second to stomach cancer in men and breast cancer in women. ${ }^{(8)}$

As shown in Figure 1-e colorectal cancer 5 -year survival is greatly affected by the stage of the cancer, with survival rates for stages I and IV being at the extremes of the survival spectrum. Similar results were found in different studies, from $90 \% 5$-year survival rates for cancers being diagnosed in localized stages to nearly $10 \%$ survival for metastatic cancers. ${ }^{(16)}$ Survival rates for colorectal cancers have increased throughout the years. ${ }^{(16)}$ Even though the incidence is higher in developed countries, due to still lower survival rates in developing countries the overall mortality in developed and developing countries are somewhat close. ${ }^{(2)}$ In Asian countries, the overall
5 -year survival rates of colorectal cancer is around $60 \%,{ }^{(17)}$ with China having recently reported 1-, 2-, 3-, 4-, and 5-year survival rates of $80.73,74.12,64.74,61.37$ and $52.37 \%$ for all CRC patients, respectively. ${ }^{(18)}$ As per the surveillance, epidemiology, and end results (SEER) database, 5-year relative survival rates for colon and rectal cancer for all stages combined were $63 \%$ and $67 \%$ respectively, in the United States. ${ }^{(19)}$ Our study yielded a 5-year survival rate of $49.8 \%$, which was lower than in most developed countries but similar to other Asian countries. ${ }^{(18)}$

Around $39 \%$ of colorectal cancers were diagnosed in the early stages. ${ }^{(16)}$ The current study yielded somewhat similar results as the percentage of patients being diagnosed with colorectal cancers in stage 0 , I, II was $32.28 \%$. These results show the importance of early screening and diagnosis of colorectal cancers. Yet the lower percentage of patients in the earlier stages may be the reason for the somewhat higher mortality rates in the present study compared to China and the United States. Stage, grade and morphology of the cancer are factors that seem to have an effect on the survival rate, as the mortality hazard for stage IV was 53.05 times higher than for stage I cancers. Although the effect of grade was not as strong as that of the stage of cancer, still, grade III cancers had a 2.25 fold higher mortality hazard than grade I. Similar results were reported both in Iran and in different parts of the world. ${ }^{(10,20-24)}$ As Saadati et al. ${ }^{(10)}$ and Hassan et al. ${ }^{(23)}$ reported, sex was a prognostic factor in colorectal cancers both in Iran and Malaysia, but in the majority of studies, sex did not have a prognostic value. ${ }^{(20,25-27)} \mathrm{We}$ did not find a significant relationship between sex and mortality either; yet the incidence was higher in men than in women, with a male: female ratio of 1.31. This was similar to previous reports from East Azerbaijan, ${ }^{(8)}$ Iran ${ }^{(15)}$ and the world. ${ }^{(2)}$

Age was a prognostic factor mentioned in some studies, as higher age relates to poor prognosis and lower 5-year survival rate. ${ }^{(10,28,29)}$ Applying additive hazard models revealed that 
increasing age of CRC patients significantly increased the mortality hazard rate and remained in effect over the entire time of the period, signifying that age at first diagnosis of CRC was not dependent on the time of diagnosis. ${ }^{(29)}$ Also during a systematic review of 28 studies from different parts of Iran, 12 studies revealed an association between age and CRC prognosis, in that about $12 \%$ of these patients were younger than 40 years. ${ }^{(11)}$ However in another group of studies age was not reported as an important prognostic factor. ${ }^{(30,31)}$ It has been elucidated that age at diagnosis has no impact on colorectal cancer specific survival rates, but has an impact on deaths due to other causes and on hazard ratio of age at first diagnosis of colorectal cancer. ${ }^{(32)}$ However our results in relation to effects of age were similar to those of the latter group, as there was no significant difference between patients younger than 50 years and older than 50 years of age in terms of mortality hazard.

The most important limitation of this study was the lack of contact information on some of the patients that limited the survival analysis to $60 \%$ percent of the diagnosed patients. Another limitation was due to the stage of the disease not being a mandatory factor in the recent Iranian National Cancer Registry program, and so staging was not available for all of the colorectal cancers. However, with the aim to achieve a more complete data set, another national program has recently been initiated and is ongoing in Iran for cancer staging. The strength of our study lies in the fact that our work is based on the East Azerbaijan populationbased cancer registry (EA-PBCR) which is one of the best and most reliable population-based cancer databases created in recent years in Iran. Overall, population-based cancer registries are a great resource for epidemiological studies about cancers and EA-PBCR is an ongoing project, helping to improve the quality of data available on cancer patients. Our aim is to improve the quality indicators and coverage of EA-PBCR in the near future.
In view of the recent improvement of prognosis and overall survival rates in most developed countries, due to effective and population-based early diagnosis and prevention programs, it is necessary to thoroughly determine the total impact of clinico-pathological factors on survival rates and prognosis of colorectal cancer patients. A priority of Iranian health policy must be to develop an executive plan to identify the most appropriate risk assessment tool, screening method, and target age group for colorectal cancer.

\section{CONCLUSION}

Our data showed that the stage and grade of colorectal cancers are important prognostic factors. Because the patients' age and sex and the subsite of the cancers were not significant prognostic factors in this study, additional studies are needed, as they will be most helpful in determining the effect of cancer morphology and other clinic-pathological factors.

\section{CONFLICT OF INTEREST}

The authors report no conflicts of interest in this work.

\section{ACKNOWLEDGMENTS}

We would like to acknowledge the support of the Hematology and Oncology Research Center for this study as an approved research proposal and Dr Ramin Barnous' doctoral thesis (Thesis no: 60473; IR.TBZMED.REC.1398. 1002).

\section{CONTRIBUTORS}

$\mathrm{RB}$ and $\mathrm{RD}$ contributed to conception and design, provision of study material or patients, data analysis and interpretation. MHS and ZS contributed to administrative support. RB and PJ contributed to collection and assembly of data. $\mathrm{RB}, \mathrm{RD}$, and ND contributed to manuscript 
writing and reviewing. All authors approved the final manuscript. All authors take public responsibility for the content of the manuscript submitted to Universa Medicina.

\section{FUNDING}

This study was supported and funded based on Population Based Cancer Registry program of East Azerbaijan from the Ministry of Health and Medical Education, Deputy of Research Technology (Grant Number: 700/1480,1395.10.4).

\section{DATA AVAILABILITY}

Data are openly available in a public repository that issues datasets with the responsibility of the corresponding author.

\section{CONSENT FOR PUBLICATION}

As per the ethics rules of EA-PBCR, all patient information and records are confidential.

\section{AVAILABILITY OF DATA AND MATERIAL}

The datasets analyzed and presented in this study are available from the corresponding author on reasonable request.

\section{REFERENCES}

1. Sung H, Ferlay J, Siegel RL, et al. Global cancer statistics 2020: GLOBOCAN estimates of incidence and mortality worldwide for 36 cancers in 185 countries. CA Cancer J Clin 2021;71:20949. doi:10.3322/caac. 21660 .

2. Bray F, Ferlay J, Soerjomataram I, Siegel RL, Torre LA, Jemal A. Global cancer statistics 2018: GLOBOCAN estimates of incidence and mortality worldwide for 36 cancers in 185 countries. CA Cancer J Clin 2018;68:394-424. doi: 10.3322/ caac.21492.

3. International Agency for Research on Cancer. Islamic Republic of Iran. The global cancer observatory;2021.

4. Arnold M, Sierra MS, Laversanne M, Soerjomataram I, Jemal A, Bray F. Global patterns and trends in colorectal cancer incidence and mortality. Gut 2017;66:683-91. doi: 10.1136/gutjnl2015-310912.

5. Hasanpour-Heidari S, Fazel A, Semnani S, et al. Temporal and geographical variations in colorectal cancer incidence in Northern Iran 20042013. Cancer Epidemiol 2019;59:143-7. doi: 10.1016 /j.canep.2019.02.003.

6. Roshandel G, Ghanbari-Motlagh A, Partovipour E, et al. Cancer incidence in Iran in 2014: results of the Iranian National Population-based Cancer Registry. Cancer Epidemiol 2019;61:50-8. doi: 10.1016/j.canep.2019.05.009.

7. Somi MH, Dolatkhah R, Sepahi S, Belalzadeh M, Naghashi S, Asghari Jafarabadi M. A 12-year trend analysis of the incidence of gastrointestinal cancers in East Azerbaijan: last updated results of an ongoing population-based cancer registry. BMC Cancer 2019;19:782. doi: 10.1186/s12885019-6008-3.

8. Somi MH, Dolatkhah R, Sepahi S, et al. Cancer incidence in the East Azerbaijan province of Iran in 2015-2016: results of a population-based cancer registry. BMC Public Health 2018;18:1266. https:/ /doi.org/10.1186/s12889-018-6119-9.

9. Maajani K, Khodadost M, Fattahi A, et al. Survival rate of colorectal cancer in Iran: A systematic review and meta-analysis. Asian Pac J Cancer Prev 2019;20:13-21. doi: 10.31557/APJCP.2019.20.1.13.

10. Saadati HM, Khodamoradi F, Salehiniya H. Associated factors of survival rate and screening for colorectal cancer in Iran: a systematic review. J Gastrointest Cancer 2020;51:401-11. doi: 10.1007/ s12029-019-00275-0.

11. Tahmasbi B, Abedi G, Moosazadeh M, et al. Determining the survival rate of colorectal cancer in Iran: a systematic review and meta-analysis. Asian Pac J Cancer Prev 2018;19:3009-18. doi: 10.31557/APJCP.2018.19.11.3009.

12. Dolatkhah R, Somi MH, Kermani IA, et al. Increased colorectal cancer incidence in Iran: a systematic review and meta-analysis. BMC Public Health 2015;15:997. doi: 10.1186/s12889-015-23429.

13. Khanali J, Kolahi AA. National and subnational cancer incidence for 22 cancer groups, 2000 to 2016: a study based on cancer registration data of Iran. J Cancer Epidemiol 2021;2021:6676666. doi:10.1155/2021/6676666.

14. Young C, Wood HM, Seshadri RA, et al. The colorectal cancer-associated faecal microbiome of developing countries resembles that of developed countries. Genome Med 2021;13:27. doi: 10.1186/s13073-021-00844-8.

15. Roshandel G, Ghanbari-Motlagh A, Partovipour E, et al. Cancer incidence in Iran in 2014: results 
of the Iranian national population-based cancer registry. Cancer Epidemiol 2019;61:50-8. doi: 10.1016/j.canep.2019.05.009.

16. Fitzmaurice C, Abate D, Abbasi N, et al. Global, regional, and national cancer incidence, mortality, years of life lost, years lived with disability, and disability-adjusted life-years for 29 cancer groups, 1990 to 2017: a systematic analysis for the Global Burden of Disease study. JAMA Oncol 2019;5: 1749-68. doi: 10.1001/jamaoncol.2019.2996.

17. Cheung KS, Chen L, Seto WK, Leung WK. Epidemiology, characteristics, and survival of post-colonoscopy colorectal cancer in Asia: A population-based study. J Gastroenterol Hepatol 2019;34:1545-53. doi: 10.1111/jgh.14674.

18. Li X, Zhou Y, Luo Z, et al. The impact of screening on the survival of colorectal cancer in Shanghai, China: a population based study. BMC Public Health 2019;19:1016. doi: 10.1186/s12889-0197318-8.

19. American Cancer Society. Survival rates for colorectal cancer. Atlanta: American Cancer Society;2021.

20. Kassim SA, Tang W, Abbas M, et al. Clinicopathologic and epidemiological characteristics of prognostic factors in postsurgical survival of colorectal cancer patients in Jiangsu Province, China. Cancer Epidemiol 2019; 62:101565. doi:10.1016/j.canep.2019.07.004.

21. Almansoori A, Alzaabi M, Alketbi L. Colorectal cancer screening in ambulatory healthcare service clinics in Abu Dhabi, United Arab Emirates in 20152016. BMC Cancer 2021;21:897. doi: 10.1186/ s12885-021-08623-9.

22. Hassan MRA, Suan MA, Soelar SA, Mohammed NS, Ismail I, Ahmad F. Survival analysis and prognostic factors for colorectal cancer patients in Malaysia. Asian Pac J Cancer Prev 2016;17: 3575-81.

23. Rasouli MA, Moradi G, Roshani D, Nikkhoo B, Ghaderi E, Ghaytasi B. Prognostic factors and survival of colorectal cancer in Kurdistan province, Iran: a population-based study (20092014). Medicine (Baltimore) 2017;96:e5941. doi:10.1097/MD.0000000000005941.

24. Vasudevan S, Mehta A. Clinical characteristics and survival profile of young versus old colorectal cancer patients at a tertiary cancer center in North India over a period of 5 years. Indian J Cancer 2020. doi: 10.4103/ijc.IJC_246_19.
25. Hu S, Li S, Teng D, et al. Analysis of risk factors and prognosis of 253 lymph node metastasis in colorectal cancer patients. BMC Surg 2021;21:280. doi: 10.1186/s12893-021-01276-2.

26. Destri GL, Barchitta M, Pesce A, et al. Predictive value of the number of harvested lymph nodes and cut-off for lymph node ratio in the prognosis of stage II and III colorectal cancer patients. J Invest Surg 2019;32:1-7. doi:10.1080/08941939. 2017.1369605.

27. Li Q, Wang G, Luo J, Li B, Chen W. Clinicopathological factors associated with synchronous distant metastasis and prognosis of stage T1 colorectal cancer patients. Sci Rep 2021;11:8722. doi:10.1038/s41598-021-87929-x.

28. Borumandnia N, Doosti H, Jalali A, et al. Nomogram to predict the overall survival of colorectal cancer patients: a multicenter national study. Int J Environ Res Public Health 2021;18: 7734. doi:10.3390/ijerph18157734.

29. Madadizadeh F, Ghanbarnejad A, Ghavami V, Bandamiri MZ, Mohammadianpanah M. Applying additive hazards models for analyzing survival in patients with colorectal cancer in Fars Province, Southern Iran. Asian Pac J Cancer Prev 2017;18:1077-83. doi: 10.22034/APJCP.2017. 18.4.1077.

30. Hosseini SV, RezaianzadehA, Rahimikazerooni S, et al. Prognostic factors of rectal cancer in Southern Iran. J Gastrointest Cancer 2020. doi: 10.1007/s12029-020-00553-2.

31. Jalaeikhoo H, Khajeh-Mehrizi A, Zokaasadi M, et al. Sixteen years of experience with the treatment of advanced colorectal cancer in Iran; a report from three institutions. Middle East J Dig Dis 2018;10:160-8. doi: 10.15171/mejdd.2018.105.

32. Moamer S, Baghestani A, Pourhoseingholi MA, Hajizadeh N, Ahmadi F, Norouzinia M. Evaluation of prognostic factors effect on survival time in patients with colorectal cancer, based on Weibull Competing-Risks Model. Gastroenterol Hepatol Bed Bench 2017;10:54-9. 